the metal bunks, and can be rapidly disinfected by either fumigation or solutions. The air supply here is entirely from leakage and one port hole, facilitated by an exhaust blower which evacuates the air and conducts it to the exterior at the stern of the ship.

On the superstructure of the ship a tent (Fig. 4) can be pitched for additional cases in case of an epidemic and at other times used for phthisis and pneumonia cases.

There are aboard about 650 men including the

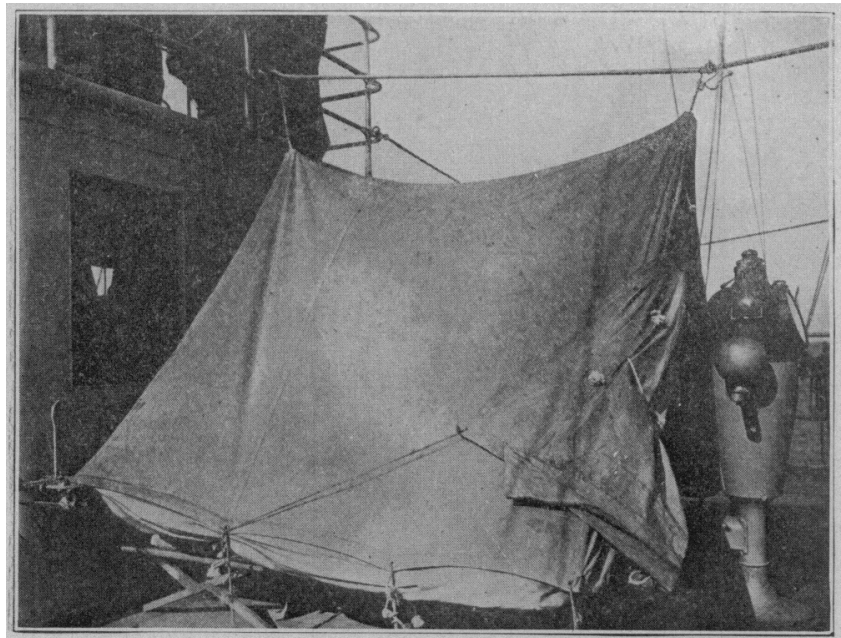

Fig. 4.-Tent for the treatment of tuberculosis and pneumonia located on the after bridge.

officers. For this complement there are one hospital steward, two hospital apprentices, first class, and one hospital apprentice (Fig. 5).

Hospital stewards are usually graduates of a college of pharmacy or have equivalent experience; hospital apprentices, first class, are graduates of a naval training school in most cases and have passed an examination for the grade. The hospital apprentices are recruited from civil life and need merely possess a general education. Besides having a knowledge of their profession,

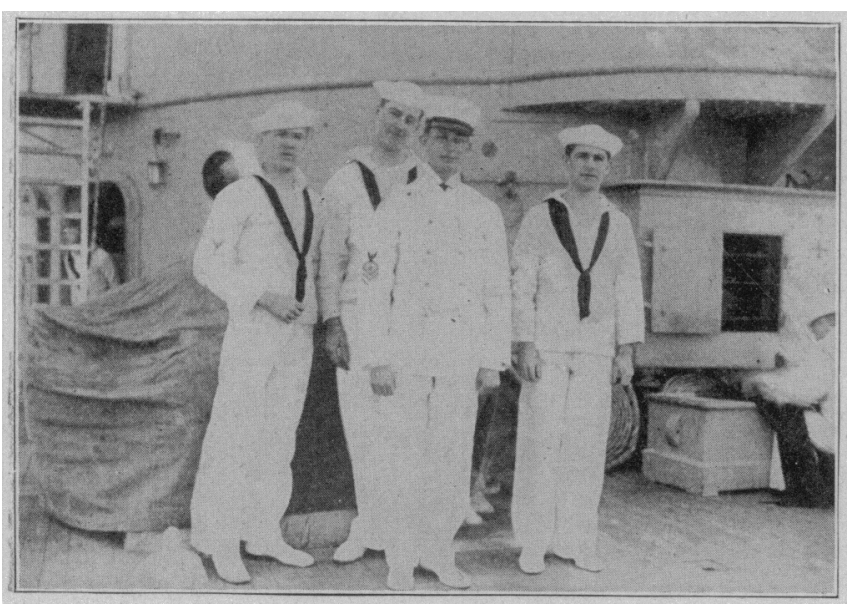

Fig. 5.-Trained hospital corps.

these men are drilled in the special requirements of a military organization.

In this connection it might be well to add that no little part of the medical officer's time and attention are given to working out preparations for conditions in the result of actual warfare. First aid instruction is given to every man on the ship. To some showing adaptability more adranced training is allowed for the purpose of using them in time of battle as assistants to the regular hospital force.

Drills are held aboard ship simulating actual battle, and at these times the medical corps assumes positions at relief and dressing stations, established with a view to prompt and systematic aid to the wounded of the crew in mind, and makes all the preparations that would be necessitated by a real engagement.

It has taken some years and much labor in the face of difficulties to bring the medical department of a ship to its present state. Confronted by the problems of crowding a great deal into a small space, arranging rooms to conform best with the architecture of a ship, allowing for a wide range of climatic conditions, beset with questions of ventilation, unusual ship motion and distance from a supply source, the results have been very satisfactory and the benefit to the naval personnel marked.

\section{AN IMPROVISED REFLECTOR FOR THROAT EXAMINATION.}

\section{J. HARVIE DEW, M.D. NEW YORK CITY.}

I have used the following simple device for a number of years in making examinations of the throat:

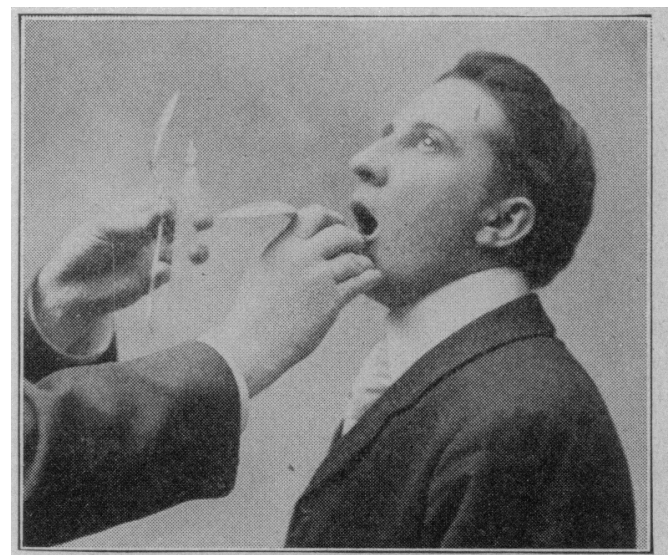

Showing method of using an improvised reflector in throat examinations.

It will prove of exceeding value whenever it is difficult to secure satisfactory light.

The idea was not original with myself nor was it obtained from any professional sources.

A candle, a tablespoon and another spoon suitable for depressing the tongue are the several essentials needed. The accompanying cut illustrates the procedure.

Hold the candle between the middle and ring fingers and the fore and little fingers of the left hand; then place the tablespoon between the thumb and fore and little fingers of the same hand. The concave bowl of the spoon should be placed immediately in rear of the flame. In this way a bright light can be thrown on any desired point.

Eczema of Extremities.-N. E. Aronstam, in Medical Fortnightly, says that, in acute erythematous eczema of the extremities, in which the subjective symptoms are very pronounced and annoying, the application of a dilute solution of the adrenal principle to the lesions will produce a rapid blanching of the parts and ameliorate the intolerable itching. After the acute features of this dermatosis have subsided an ordinary Lassar's paste with or without ichthyol wherein a small amount of adrenalin solution has been incorporated, will hasten the restitution of the involved areas to normal. 